\title{
Editorial
}

\section{Recovery and the medical model ${ }^{\dagger}$}

\author{
Deborah Mountain \& Premal J. Shah
}

\begin{abstract}
The recovery approach is much in vogue, initiated by the user movement and embraced by politicians. Users and politicians have a variety of opinions about how it fits with professional psychiatric practice - some view recovery and professional practice as compatible, others view them as mutually exclusive, naming professional practice the 'medical model'. This editorial explores the relationship between the medical model and the recovery approach. We argue that both have multiple points of similarity, and that applying the medical model to the recovery approach has the potential to significantly influence psychiatric practice.
\end{abstract}

The 'recovery approach' is currently favoured by both politicians and patients in the UK (Department of Health 2001; Expert Group on Mental Health Policy, 2006; Scottish Executive, 2006) and it is shaping contemporary mental health strategy. However, many psychiatrists seem detached from this approach. Sceptics suggest that it underplays the value of psychiatric treatment and services and offers false hope. Others see it as a challenge to the medical model and practice. There is therefore a need to examine what is defined as recovery and to explore the relationship between the recovery approach and the medical model and the implications of this relationship for medical practice.

\section{What is recovery?}

Defining 'recovery' is difficult, as health professionals and users understand it in a variety of ways. As Jacobson \& Greenley (2001) have noted,

'Recovery is variously described as something that individuals experience, that services promote, and that systems facilitate, yet the specifics of exactly what is to be experienced, promoted, or facilitated - and how are often not well understood either by the consumers who are expected to recover or by the professionals and policy makers who are expected to help them.'

${ }^{\dagger}$ For a commentary on this Editorial, see pp. 245-247, this issue.
Diverse definitions may be related to the difference between someone 'having recovered' and 'being in recovery'. The former accords with the conventional definition of 'a cure or restoration to former health and stability' (Shorter Oxford Dictionary) or 'regaining something lost' (Wikipedia). The latter, used by the recovery movement and particularly by people with longer-term conditions, expands the definition to a 'personal process, way of life or attitude, involving the growth of new meaning and purpose beyond the effects of mental illness' (Deegan, 2003). This parallels Davidson et al's (2006) two models of recovery of which the first refers to recovery in the conventional sense, and the second to restoring health in the broader sense - a sense of well-being regardless of symptoms. The latter is brought about by the person's efforts to live in 'meaningful and gratifying ways despite limitations imposed by enduring disability'. These two views could be regarded as being so divergent as to represent a change in the use of language (Oyebode, 2004), but we believe that they are not as separate as may be thought.

The key is in understanding the concept of health, and recovery as the restoration of health as a whole. Health has been defined not only as the narrow experience of bodily function or absence of symptoms, but also a set of capacities involving 'the ability to respond to challenges and restore a state of balance' (Wikipedia). Restoring good health, then, would involve the development or rehabilitation of these capacities - that is, helping

Deborah Mountain is a consultant in rehabilitation and psychiatric intensive care at the Royal Edinburgh Hospital (Morningside Terrace, Edinburgh EH10 5HF, UK. Email: debbie.mountain@lpct.scot.nhs.uk). Her interests are social psychiatry and recovery. Premal J. Shah is a consultant in general and community psychiatry and honorary senior lecturer, also at the Royal Edinburgh Hospital. His interests are the neurobiology of mental disorders, and the public perception of psychiatry. 
to support a person's efforts to live a meaningful life despite disability.

\section{Recovery and the medical model}

The recovery literature often refers to the 'medical model', encouraging speculation that the recovery approach and the medical model are competing concepts that at best tolerate or complement each other. Some (Roberts \& Wolfson, 2004) describe the medical model as a concept defined by non-doctors, who portray psychiatric practice as narrow and focused on disease and symptoms.

We have recently (Shah \& Mountain, 2007) proposed that the medical model is a process whereby doctors advise on, coordinate or deliver health-improving interventions informed by the best available evidence. It applies to any treatment modality or approach and it is embodied in the question 'does it work?'. This necessarily means that medical interventions constantly evolve as new evidence refines treatments and as shifts in paradigm innovate new treatments. Thus, since patients have found that the recovery approach works, it warrants systematic investigation. The process of objectively defining 'what works' within the recovery approach is the medical model. The medical model, then, is not divorced from the recovery approach, but instead is critical in identifying its specific effective components. The potential of this approach is to produce sufficient adequate evidence to justify modifying current psychiatric practice. Not to embrace change, as observed by Engel (1977), would be professional dogma. Thus, it may not be the medical model itself that needs to be questioned, but how that model informs current psychiatric practice.

\section{Recovery, the medical model and psychiatric practice}

We believe that psychiatry can be practised in a way that maintains its professional integrity while incorporating the process of recovery as described by the recovery movement. In many ways, good medical practice already has components in tune with recovery. There are, however, some areas of 'being in recovery' (for example, encouraging individuals to take responsibility for maintaining their health and to examine how identity and sense of self affect their ability to keep well) where practice may need to be modified.

Because 'recovery' can be defined in several different ways, many themes are identified in the literature. Jacobson \& Greenley (2001), for example, have conceptualised internal and external key conditions for recovery, these being hope, healing, empowerment, connection, human rights, a positive culture of healing and recovery-oriented services. Derived from themes such as these, Resnick et al (2004) have empirically identified four components that may correlate with recovery: life satisfaction, hope and optimism, empowerment, and knowledge about mental illness and services. In the following sections we use these components as a framework within which the relationship between recovery and the medical model can be further examined and implications for psychiatric practice discussed.

\section{Life satisfaction}

Some in the recovery movement believe that medical practice concentrates on 'symptoms' and excludes accounts of individuals' experience or satisfaction with life. Lehman (1983) notes that life satisfaction is of great importance to individual patients. However, by their nature symptoms are the patient's subjective description of their physical or mental feelings and sensations. Formal ratings of symptoms, such as the Hamilton Rating Scale for Depression (Hamilton,1967), may be seen as 'disease-specific' measures but they also correlate with quality of life and life satisfaction (Zimmerman et al, 2006). Life satisfaction is related not only to measures of symptoms, but also to self-perceived health (Al-Windi, 2005). Self-evaluation is therefore important. Current psychiatric practice captures important information about a patient (their symptoms) relating to their life satisfaction, but there may be other aspects of life satisfaction that are overlooked. Good psychiatric practice elicits symptoms but also explores the meaning they have for the patient (for example, the content of psychotic experiences often reflects aspects of the patient's real-life experience). In essence, the recovery approach and the medical model have similarities, but practice could improve to take greater account of patients' own perceptions of their health and what their symptoms mean to them, both of which are important to life satisfaction.

\section{Hope and optimism}

The recovery movement believes that hope and optimism can be encouraged by recounting individual 'stories'. Doctors take histories (stories) for diagnostic and treatment purposes. In recovery, individuals' own stories are used to highlight their strengths and experiences in the context of their life - something that current psychiatric practice may neglect, especially as treatment becomes more protocolised. 
Some in the recovery movement recoil from using diagnoses. This probably partly originates in the assumption long held by the public and doctors that serious psychiatric conditions/diagnoses have hopeless outcomes. Although a Kraepelinian approach may have encouraged this view, contemporary medical studies using diagnostic groupings have found positive outcomes for illnesses previously regarded as permanently disabling. The recovery movement's drive for hope and optimism does, therefore, parallel the message emerging from conventional science. The agenda should therefore be to change peoples' assumptions about mental illness, not to dispose of diagnoses.

\section{Empowerment}

Some proponents of the recovery movement assume that patients are automatically disempowered by their contact with doctors, leaving them passive and in need of 'empowerment'. However, leaders of some patient groups have observed that empowerment by 'consumerism' might feed 'people's sense of fragility, ... discouraging individual responsibility' (Tallis, 2004: pp. 101-102). Passivity does not fit with what is expected of the contemporary doctor-patient relationship (General Medical Council, 2006: p. 15). It is now expected that patients are active participants in their care and that the doctor-patient relationship is founded on engagement and the recognition of the skills and knowledge of each partner. This relationship is deployed to set goals and encourage participation in treatment (Berzins, 2006). Within this, one of the patients' active roles is the effort they are expected to make to move on with their lives. These expectations parallel the advocacy in the recovery approach that recovery is owned by the patient (client) and that professionals and services facilitate it. Promoting self-control, selfmanagement and personal responsibility and supporting patients to believe that they can shape their future are therefore aspects of good medical practice. However, special effort may be required to support these in everyday practice as they may not be part of routine care.

It could be argued that medical and recovery practices part company by use of compulsion. ${ }^{\ddagger}$ However, compulsion is only one component of care on the journey to being in recovery. Thus, although this may be a time when differences between doctor and patient need to be tolerated, even the most

‡Patient choice in compulsory detention was the subject of a series of articles in the previous issue of APT $(2008,14(3))$ : see Roberts et al, 172-180; Copeland \& Mead, 181-182; Fulford \& King, 183-184; Dorkins et al, 184-186. Ed. interventionist psychiatrist can encourage an alliance with the patient, managing conflict and designing care that promotes and optimises the patient's selfmanagement.

\section{Knowledge}

Resnick et al's (2004) research explores recovery in relation to knowledge about illness and mental health services. The recovery movement likewise values knowledge about illness, but it also values knowledge derived from unique individual experiences/stories. Both the medical model and the recovery movement consider knowledge to be important, but some in recovery criticise conventional science's knowledge on at least two fronts. The first is its reliance on depersonalised aggregate measures based on diagnosis. The second is the use of outcomes such as hospital admissions, symptoms and length of hospital stay for its evidence base instead of 'personally meaningful' outcomes.

As regards the first criticism, traditional aggregate outcome studies in fact support the recovery movement's message, by demonstrating that significant numbers of people do recover (Coryell \& Tsuang, 1986; Kennedy et al, 2004). Furthermore, the recovery movement's current emphasis on qualitative research accords with the process of scientific advancement that has been operating in medicine for decades. Story-telling, a process promoted by the recovery movement, is effectively a form of case reporting, with the process elucidating individuals' strengths and abilities - in effect, resilience factors. In medicine, case reporting is the first step from qualitative to quantitative research. Progress from case report to quantitative study is a well-established method of identifying and testing out new therapeutic measures. The same process could be useful in identifying the important components of 'being in recovery'. Indeed, there is already literature about the process of recovery and coping styles (Thompson et al, 2003), forming the beginnings of an evidence base.

The second criticism is curious. Outcomes such as repeated hospital admissions are important to individuals as they can be highly disruptive and chaotic and are a proxy of relapse (Burns, 2007). They are thus worthy of study, even if only to find out what works to reduce them. This evidence could therefore be one aspect of studying recovery. Moreover, although it is true that earlier studies used easily defined outcome measures, contemporary studies use more functional measures or ones of greater relevance to the individual (for example, quality-of-life measures). It is important to be open to reevaluating and changing practice as these outcomes become known. 


\section{How should psychiatrists respond to the recovery movement?}

There have been a confusing range of responses among psychiatrists. Some have been bemused, dismissive or defensive. Others have said 'We are doing this already'. However, this reply fosters complacency and does not acknowledge that this cannot always be the case, given the previous pessimistic view of chronicity and the legacy of some past psychiatric practice. Some have become apologists, colluding with the distorted view of the medical model; some sceptically believe that psychiatry may simply respond by rebranding current practice with 'recovery', to make it more fashionable.

We do not advocate that the profession fundamentally changes itself, or undergoes rebadging. Good doctors attend to the person as well as to the illness. Good doctors and psychiatrists also use the best available evidence - the medical model - to promote hope, encourage self-management, maximise strengths, and support patients to rediscover meaning and purpose for themselves. Given these challenges, we should be proud to recognise ourselves as doctors within the dynamic relationship with patients, and doctors who strive to shape services that facilitate recovery.

\section{Declaration of interest}

None.

\section{References}

Al-Windi, A. (2005) The relations between symptoms, somatic and psychiatric conditions, life satisfaction and perceived health. A primary care based study. Health and Quality of Life Outcomes, 3, 28-37.

Berzins, K. (2006) Implementing a Recovery Approach in Policy and Practice: A Review of the Literature. Public Health \& Health Policy, University of Glasgow (http: / / www.scottishrecovery. net/content/mediaassets/doc/Berzins\%20report.pdf).
Burns, T. (2007) Hospitalisation as an outcome measure in schizophrenia. British Journal of Psychiatry, 191 (suppl. 50), 37-41.

Coryell, W. \& Tsuang, M. (1986) Outcome after 40 year in DSM-III schizophreniform disorder. Archives of General Psychiatry, 43, 324-328.

Davidson, L., Lawless, M. S. \& Leary, F. (2006) Concepts of recovery: competing or complementary. Current Opinion in Psychiatry, 19 (suppl. 6), 619-624.

Deegan, G. (2003) Discovering recovery. Psychiatric Rehabilitation Journal, 26 (suppl. 4), 368-376.

Department of Health (2001) The Journey to Recovery: The Government's Vision for Mental Health Care. UK Department of Health.

Engel, G. (1977) The need for a new medical model: a challenge for biomedicine. Science, 196 (suppl. 428), 129-136.

Expert Group on Mental Health Policy (2006) A Vision for Change: Report of the Expert Group on Mental Health Policy. Stationery Office Dublin.

General Medical Council (2006) Good Medical Practice. GMC.

Hamilton, M. (1967) Development of a rating scale for primary depressive illness. British Journal of Social and Clinical Psychology, 6, 278-296.

Jacobson, N. \& Greenley, D. (2001) What is recovery? A conceptual model and explication. Psychiatric Services, 52, 482-485.

Kennedy, N., Abbott, R. \& Paykel, E. S. (2004) Longitudinal syndrome and sub-syndromal symptoms after severe depression: 10-year follow-up study. British Journal of Psychiatry, 184, 330-336.

Lehman, A. F. (1983) The well-being of chronic mental patients. Assessing their quality of life. Archives of General Psychiatry, 40, 369-373.

Oyebode, F. (2004) Invited commentary on: The rediscovery of recovery. Advances in Psychiatric Treatment, 10, 48-49.

Resnick, S. G., Rosenheck, R. A. \& Lehman, A. F. (2004) An exploratory analysis of correlates of recovery. Psychiatric Services, 55, 540-547.

Roberts, G. \& Wolfson, P. (2004) The rediscovery of recovery: open to all. Advances in Psychiatric Treatment, 10, 37-48.

Scottish Executive (2006) Delivering for Mental Health. Scottish Executive.

Shah, P. \& Mountain, D. (2007) The medical model is dead long live the medical model. British Journal of Psychiatry, 191, 375-377.

Tallis, R. (2004) Hippocratic Oaths - Medicine and its Discontents. Atlantic Books.

Thompson, K., McGorry, P. \& Harrigan, S. (2003) Recovery style and outcome in first episode psychosis. Schizophrenia Research, 62 (suppl. 1-2), 31-36.

Zimmerman, M., Ruggero, C. J., Chelminski, I., et al (2006) Developing brief scales for use in clinical practice: the reliability and validity of single-item self-report measures of depression symptom severity, psychosocial impairment due to depression, and quality of life. Journal of Clinical Psychiatry, 67 (suppl. 10), 1536-1541. 